\title{
Application of ANN in Milling Process: A Review
}

\author{
Salah Al-Zubaidi, Jaharah A. Ghani, and Che Hassan Che Haron \\ Department of Mechanical and Material Engineering, Faculty of Engineering and Built Environment, \\ National University of Malaysia, Selangor, 43600 Bangi, Malaysia
}

Correspondence should be addressed to Salah Al-Zubaidi, salah@eng.ukm.my

Received 16 December 2010; Accepted 14 March 2011

Academic Editor: Agostino Bruzzone

Copyright (c) 2011 Salah Al-Zubaidi et al. This is an open access article distributed under the Creative Commons Attribution License, which permits unrestricted use, distribution, and reproduction in any medium, provided the original work is properly cited.

\begin{abstract}
In recent years the trends were towards modeling of machining using artificial intelligence. ANN is considered one of the important methods of artificial intelligence in the modeling of nonlinear problems like machining processes. Artificial neural networks show good capability in prediction and optimization of machining processes compared with traditional methods. In view of the importance of artificial neural networks in machining, this paper is an attempt to review the previous studies and investigations on the application of artificial neural networks in the milling process for the last decade.
\end{abstract}

\section{Introduction}

The milling process is one of the important machining processes besides turning. In the milling process the chips are removed by feeding a work piece past a rotating multiple tooth cutter. It is a complex process, where analytical models cannot give the best accurate results in modeling. Traditional methods like statistical regression and response surface methodology approaches have been used by some researchers in modeling the milling process. But these methods cannot overcome the nonlinearity of relationships between cutting conditions and the output response.

ANN models are able to solve these problems encountered in the machining process through its massive parallelization to solve complex nonlinear problems. Artificial neural networks are computational networks that have the ability to simulate neurons in biological nerve centers [1]. ANN consists of simple processing units in a parallel sequence. The connections between these units will specify the network function and performance. For the doing of some tasks or functions ANN can be trained by adjusting the connection strength (weights) between units [2]. Figure 1 illustrates what is mentioned above.

There is a comparison between the output and the target in order to reach the target output. The network needs input/output pairs for training and adjusting the connection values. ANN shows capability in solving many problems in many applications like pattern recognition, classification, prediction, optimization, and control systems.

The following sections review some of the literature concerned with surface roughness prediction, tool life and wear estimation, and cutting force prediction using ANN.

\section{Surface Roughness}

Surface roughness plays an important role in determining the quality of the machined parts through its impact on fatigue resistance, lubrication, friction, and wear properties. Recently, there have been many studies that have been conducted for surface roughness prediction using the technique of artificial neural networks. Their results were more accurate compared to traditional statistical methods. Below is some literature concerned with this field.

Tsai et al. [3] developed an in-process surface roughness prediction system in end milling. Vibration and rotation data were collected using an accelerometer and proximity sensors. BP neural networks with four input and one output neurons, which were spindle speed, feed rate, depth of cut, and vibration average per revolution as inputs, and surface roughness as output. The system accuracy was $96.99 \%$ under various cutting conditions.

Benardos and Vosniakos [4] presented an ANN model for prediction of surface roughness. The input parameters were 
depth of cut, feed rate, cutting speed, cutting tool wear, cutting fluids, and three component cutting forces. BP neural networks were trained with the Levenberg-Marquard algorithm. The Taguchi method was used for design of the experiments. The primary factors affecting surface roughness were feed rate per tooth, Fx cutting force component, depth of cut, cutting fluids, and cutting tool wear. The mean square error was $1.86 \%$.

Zuperl et al. [5] described an adaptive neural controller that has the ability to adjust the feed rate for minimizing tool wear and maintaining a high removal rate. BP neural network was used with four input neurons represented by cutting speed, feed rate, axial and radial depth of cut, and three output neurons which were Fx, Fy, and surface roughness. The system showed high stability and robustness.

Li et al. [6] presented a hybrid radial basis approach for prediction of machining errors. According to the experimental results, the cutting speed, feed rate, axial and radial depth of cut had an effect on machining errors. The authors compared prediction models, which were radial basis function, adaptive network-based inference system, and hybrid radial basis function and found the former (radial basis) is the best in prediction of machining errors in end milling.

Ozcelik et al. [7] integrated ANN with GA to optimize cutting conditions with minimum surface roughness in end milling of Inconel 718 alloy. Statistical design of experiments was used with three-level full factorial designs. Good agreement and effective performance of the mentioned method was obtained.

Also, Oktem et al. [8] used GA supported with ANN for optimization of cutting parameters with end milling of AA 7075-T6. Feed forward backpropagation neural network with a structure of 5-42-42-1 was used. The authors found good accuracy and agreement between the experimental and predictable results.

Tansel et al. [9] proposed a genetically optimized neural network system for optimization cutting parameters in end milling for two case studies, which were POCO-3 Graphite material and AA6061 mold part alloy from experimental data. Each case study had a purpose for optimization. The first case study was to avoid tool breakage and keep the cutting force in the target range and maximization of the metal removal rate (MRR), and the second case study was to obtain a compromise between machining time and surface roughness without developing any analytical or empirical solution model. GONNS was used with a BP neural network. Good agreement was achieved between GONNS and experimental data.

Erzurumlu and Oktem [10] developed two models for surface roughness prediction in end milling of 7075-T6, which were response surface methodology (RSM) and a feed forward backpropagation neural network. The input parameters for the two models were cutting speed, feed rate, axial and radial depth of cut, and machining tolerance. The output response was surface roughness. The ANN model was slightly more accurate than the RSM model according to the authors' findings.

Huang et al. [11] applied ANN in an in-process pokayoke system in end milling of 6061-T6 in order to change

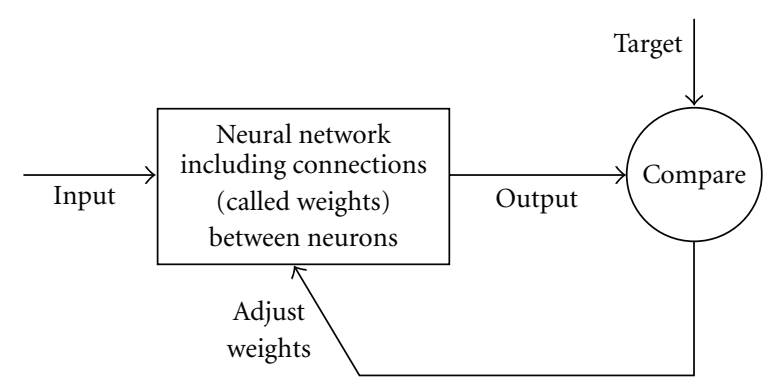

FIGURE 1

adaptive surface roughness. This system adjusted the feed rate if the surface roughness was larger than the desired surface roughness during cutting. A BP neural network with a 5-8-7-1 structure was used and trained with PCN training software. The input parameters were spindle speed, feed rate, average resultant peak force in the $x-y$ plane, absolute average force in the $z$-direction from in-process neural network surface roughness prediction and the output parameter was adaptive degree of current feed rate. The system produced an accuracy of around 90\%.

Hossain et al. [12] developed ANN to predict surface roughness during high speed machining of Inconel 718 with a single-layer PVD TiAlN insert. A BP neural network with two hidden layers having 15 neurons each, three input neurons (cutting speed, feed rate, and depth of cut), and one output neuron (surface roughness). The model had good accuracy and was efficient enough.

El-Sonbaty et al. [13] predicted a surface roughness profile using a feed forward backpropagation neural network with four different structures: 5-5-1, 5-10-1, 5-15-1, and 520-1. The input layer consisted of five neurons: spindle speed, feed, depth of cut, and pre-tool wear vibration level. The output layer had two neurons: fractal dimension parameters $D$ and vertical scaling parameter $G$, which characterize the machined surface profile. Structure 5-5-1 was the best structure among all the structures with an accuracy of $98 \%$.

Liu et al. [14] developed an ANN model to predict surface roughness. Different network structures were used in order to select the best one with the minimum error. Cutting speed, feed rate, axial depth of cut, and radial depth of cut were considered as input parameters while surface roughness was an output response. A BP neural network trained with the Levenberg-Marquard algorithm was used. 4-9-9-1 was the best structure and the predicted model showed good agreement compared to the experimental results.

Quintana et al. [15] developed an adaptive controlled system for inline surface roughness monitoring supported with ANN. A feed forward trained with an algorithm was used.

Öktem [16] developed an ANN model coupled with GA for optimization of cutting conditions and prediction of surface roughness with end milling of AISI 1040 plain carbon steel. Also multiple regression and ANOVA were used for studying the effect of cutting conditions on surface roughness. The proposed integrated method (GA with feed 
forward BP neural networks) had reduced the machining time to $20 \%$ with accuracy and a $3.27 \%$ error.

Zain et al. [17] compared multiple regressions, MR, with ANN in prediction of minimum surface roughness. Different backpropagation networks were used. Predicted surface roughness value was below experimental and multiple regression values. Thus, the results show that the BPNN model is more accurate than the MR model.

Also as in [17] Zain et al. [18] showed from their work the capability of ANN in prediction of machining performance $\mathrm{Ra}$ in the milling process. Four different $\mathrm{BP}$ neural networks were applied. 3-7-1 was the best one where surface roughness was reduced in amount of $0.0126 \mu \mathrm{m}$ of the experimental data.

Escamilla et al. [19] integrated ANN with particle swarm optimization for prediction of surface roughness and optimization of cutting process parameters. ANN predicted surface roughness followed by PSO for optimization.

Extension to the works in [17, 18], Zain et al. [20] presented ANN for surface roughness prediction using twolevel full factorial designs. The authors gave good information and guides about how to select networks structures, amount of training and testing data, normalizing of data, and transfer, training, learning, and performance functions. The authors recommend that minimum surface roughness can be obtained with a high cutting speed, low feed rate, and rake angle.

Rashid and Abdul Lani [21] used MR and ANN in prediction of surface roughness in a CNC milling machine. BPNN was performed. ANN was approved and provided more accuracy than multiple regressions MR.

Brecher et al. [22] proposed a surface roughness monitoring system based on NC kernel data. ANN was used to predict surface roughness. Surface roughness could be monitored on-line through this system in addition to optimization of cutting parameters.

Razfar et al. [23] combined ANN with a harmony search algorithm for prediction and optimization in face milling. The approach was effective in finding the optimum surface roughness.

Huang et al. [24] presented an in-process surface roughness prediction. ANN was used for prediction. Both feed rate and cutting speed were adjusted through an adaptive neural controller to satisfy required surface roughness.

Topal [25] investigated the effect of stepover ratio in end milling on surface roughness prediction through an ANN model. Two BP neural networks with and without surface roughness were applied. The ANN model with stepover ratio gave accurate results.

Muñoz-Escalona and Maropoulos [26] developed three artificial neural network models for surface prediction in milling AA7075-T7351 alloy. The networks were feed forward, radial basis, and generalized regression networks. All the networks had five input neurons represented by cutting speed, feed rate, axial depth of cut, chip width, and chip thickness, with surface roughness as output. The mean square error was used in comparing and selecting what was the best network. The feed forward was the best one with MSE of 5.5\% but took more training time than the others.
The cutting speed had a significant effect on the surface roughness.

Palani and Natarajan [27] proposed a noncontact machine vision integrated with an artificial neural network for surface roughness prediction. The surface feature was extracted using spatial frequency based on a 2D Fourier domain. A self-organized map neural network was used with five inputs, which were cutting speed, feed rate, depth of cut, and image variables, F1, F2, and Ga, where F1 is the major peak frequency, F2 is the principal component magnitude squared value, and $\mathrm{Ga}$ is the average gray level of the surface image. The surface roughness was the output of the network. The surface roughness values determined from the system were compared with stylus surface roughness tester readings and there was an error around $5.5 \%$ with a prediction accuracy of the neural network at $97.53 \%$.

\section{Cutting Forces}

Obtaining good quality and cheap parts are the main objective of the machining processes. As cutting forces rise, the power consumption and machining costs also increase. Application of artificial neural network models for cutting force prediction are presented as follow.

Tandon and El-Mounayri [28] developed an ANN model for force prediction in flat end milling. The input layer had eight neurons (Radial Depth of Cut, Axial Depth of Cut, Feed Rate Spindle Speed, Cutter Diameter, Off Flutes, Rake Angle, and Clearance Angle), and the output layer had two neurons (maximum and mean forces). A feed forward network was used and trained with the Levenberg-Marquard algorithm. After that the model was tested in a real machining operation, called pocket milling and showed good results compared to experimental results.

Tandon et al. [29] proposed an ANN model to predict cutting forces in end milling. Particle swarm optimization used these forces predicted from ANN to optimize both the feed rate and the cutting speed. There was a reduction in machining time around $35 \%$.

Briceno [30] estimated cutting force in milling with two supervised feed forward backpropagation neural networks and a radial basis model. Orthogonal design was used for cutting experiment design. Radial basis model was superior for feed forward backpropagation.

Zuperl and Cus [31] applied backpropagation neural networks for predicting three components of cutting forces in ball end milling. The accuracy of the ANN model was 4\% compared with the analytical model, which was $11 \%$.

EL-Mounayri et al. [32] used a radial basis neural network (RBNN) for prediction of cutting forces and particle swarm optimization (PSO) for cutting conditions optimization. The accuracy of this model was $95 \%$ and there was a reduction in machining time up to $36 \%$ when PSO for a slot milling case study.

Zuperl et al. [33] developed two supervised neural network models for cutting force prediction system during ball end milling which were a feed forward backpropagation network and a radial basis network. The inputs for these 
two networks were: cutting fluids, hardness, material type, cutting tool diameter, types of insert, cutting speed, radial depth of cut, axial depth of cut, and flank wear. The outputs were Fx, Fy, and Fz. The authors found that the radial basis network is superior to the backpropagation network.

Aykut et al. [34] used ANN in face milling of satellite Cobased alloy under dry conditions to predict cutting forces. A feed forward backpropagation neural network was trained with a scale conjugate gradient. The input layer consisted of three neurons represented by cutting speed, feed rate, and depth of cut while the output layer involved three cutting force components. Different network structures were used with single hidden layers to select the best one, which was 3-35-3. There was good agreement between the ANN model experimental values.

Rai et al. [35] developed a mill-cut system to predict cutting forces and shear plane temperature during end milling. A feed forward backpropagation neural network was used that had 15 neurons corresponding to cutting tool geometrical parameters, cutting parameters, and work piece material properties. The output layers consisted of four neurons represented by three components of cutting forces and shear plane temperature. The ANN model was compared to the experimental and numerical results in the literature and showed good agreement.

Chen et al. [36] applied a backpropagation neural network for cutting forces prediction induced in end milling of hardened steel. The predictive model had an accuracy of around 5\% error, except for some individual values.

Seong et al. [37] introduced a hybrid neural network for cutting force signal detecting and classifying in end milling. The hybrid networks have both a backpropagation and self-organizing map. The model was validated using experimental tests and was shown to be well matching.

Zuperl et al. [38] designed a robust neural force controller for adjusting feed rate in end milling to minimize tool wear while maintaining a high removal rate at the same time. The cutting process parameters were optimized via coupling adaptive controls with standard numerical controls. Backpropagation neural networks were used for online modeling. The adaptive controller showed high accuracy by validating its applicability with cutting tests.

El-Mounayri et al. [39] developed an ANN model for prediction of cutting forces in a ball end milling process. Radial basis was applied for its advantages from the view of convergence speed. The networks had four inputs and outputs with single hidden layers. The input parameters were spindle speed, feed rate, and axial, and radial depth of cuts while the outputs were maximum force, minimum forces, mean force, and standard deviation of force. The authors applied this model in a real-life pocketing process and found good agreement with experiments, where the error was only $3 \%$.

Chen et al. [40] presented a cutting force prediction model in milling operation based on an artificial neural network. The input parameters were cutting velocity, feed rate, and depth of cut, and the outputs were the three components of cutting forces. There was a good correlation between the predicted cutting forces and the validating test.

\section{Tool Life and Wear}

Tool wear degrades surface quality, increases power consumption, and causes rejecting of machined parts. Many attempts have been carried out to develop artificial neural network models for estimation of tool wear.

Dutta et al. [41] investigated the ability of modified backpropagation compared with the standard propagation, in view of convergence speed and prediction accuracy in tool condition monitoring. The momentum parameter had greater effect on the convergence speed compared with the learning rate.

Haber and Alique [42] proposed an intelligent supervision system based on the ANN model to estimate tool wear in end milling in real time. The model can work properly in a real milling process.

Jacob C. Chen and Joseph C. Chen [43] proposed an online tool wear prediction system based on ANN. A feed forward backpropagation was trained and tested with 100 and 9 experimental data, respectively. Average peak force in $Y$ axis, feed rate, and depth cut were the input parameters to the network. The system gave an average error of $\pm 0.037 \mathrm{~mm}$.

Dutta et al. [44] studied the capability of a modified backpropagation neural network with a delta bar learning rate from the view of fast convergence and prediction wear accuracy of tungsten carbide inserts on face milling of steel. The authors compared the effectiveness of the mentioned modified network with BPNN, MBPNN, and FBPNN. There was a reduction in training time as a result of selecting the best process parameters and using multisensor-based tool monitoring.

Zuperl et al. [45] integrated an offline feed rate optimization and adaptive feed forward force neural controller system in a CNC milling process. The system tends to maintain a high metal removal while keeping the cutting in the desired range. Also, the system adjusted feed rate according to spindle speed and stopped the machining process when high forces were detected. The system minimizes tool wear and gave a good surface finish.

Ghosh et al. [46] developed a tool wear prediction model based on sensor fusion using a BP neural network. Cutting forces in $X$ and $Y$ directions, spindle vibration, spindle current, and sound pressure levels were gathered for tool wear estimation of the main cutting edge.

Chuangwen et al. [47] applied a backpropagation neural network in tool wear monitoring in the milling process. A 5-10-1 structure was used with five input neurons: tool diameter, spindle speed, feed speed, the spindle cutting power, feed cutting power, and the output was tool wear. The model could monitor the tool wear accurately in milling.

Guo et al. [48] developed multisensor tool wear and breakage detection by integrating two subnetworks that had been trained and tested. The output of the multisensor detection (CCD camera, acoustic emission AE, and cutting force sensor) were input to the two subnetworks and their outputs considered as inputs to an integrated neural network. The accuracy of the system was within 5\% error.

Palanisamy et al. [49] applied regression and the ANN model for tool wear estimation when end milling AISI 1020 
steel with carbide cutters. Design of the experiment was used with three full factorials having five levels. The inputs to the models were cutting speed, feed rate, and depth of cut while output response was flank wear. The authors found that the ANN model was more accurate and efficient than the regression model in prediction of flank wear.

Bruni et al. [50] proposed ANN and multiple regression models for surface roughness and tool wear monitored with cutting time when end milling AISI 420B stainless steel under different cutting conditions and different lubricants (dry, wet, and minimum lubricant quantity MQL). A feed forward BP neural network was used. Using MQL gave minimum surface roughness and tool wear, especially under high cutting speeds.

Brezak et al. [51] proposed a flank weal estimation model based on a radial basis neural network controller and a modified dynamic neural network filter. The model was analyzed with an analytical model.

\section{Conclusions}

According to the previous studies and investigations, the following conclusions can be drawn. (1) Backpropagation neural networks are the primary artificial neural network applied by researchers. (2) The ANN model showed higher accuracy than traditional statistical approaches. (3) Genetic algorithms coupled with ANN are widely used for prediction and optimization of the cutting process. (4) Some researchers developed adaptive neural controllers supported by ANN for online monitoring of either surface roughness, tool wear, or cutting forces through adjusting cutting conditions to minimize output response. (5) Most of the studies concentrated on surface roughness prediction compared with cutting forces and tool wear, due to the important role played by surface integrity of the machine parts.

\section{References}

[1] D. Graupe, Principles of Artificial Neural Networks, World Scientific, 2nd edition, 2006.

[2] M. H. Beal, M. T. Hagan, and H. B. Demuth, Neural Network ToolboxTM 7, 2010.

[3] Y. H. Tsai, J. C. Chen, and S. J. Lou, "An in-process surface recognition system based on neural networks in end milling cutting operations," International Journal of Machine Tools a\& Manufacture, vol. 39, no. 4, pp. 583-605, 1999.

[4] P. G. Benardos and G. C. Vosniakos, "Prediction of surface roughness in CNC face milling using neural networks and Taguchi's design of experiments," Robotics and ComputerIntegrated Manufacturing, vol. 18, no. 5-6, pp. 343-354, 2002.

[5] U. Zuperl, E. Kiker, and F. Cus, "Optimization in ball-end milling by using adaptive neural controller," in Proceedings of the IEEE International Conference on Industrial Technology (ICIT '03), pp. 393-398, December 2003.

[6] X. Li, X. Guan, and Y. Li, "A hybrid radial basis function neural network for dimensional error prediction in end milling," in Proceedings of the International Symposium on Neural Networks, vol. 3174 of Lecture Notes in Computer Science, pp. 743-748, Dalian, China, August 2004.
[7] B. Ozcelik, H. Oktem, and H. Kurtaran, "Optimum surface roughness in end milling Inconel 718 by coupling neural network model and genetic algorithm," International Journal of Advanced Manufacturing Technology, vol. 27, no. 3-4, pp. 234-241, 2005.

[8] H. Oktem, T. Erzurumlu, and F. Erzincanli, "Prediction of minimum surface roughness in end milling mold parts using neural network and genetic algorithm," Materials and Design, vol. 27, no. 9, pp. 735-744, 2006.

[9] I. N. Tansel, B. Ozcelik, W. Y. Bao et al., "Selection of optimal cutting conditions by using GONNS," International Journal of Machine Tools \& Manufacture, vol. 46, no. 1, pp. 26-35, 2006.

[10] T. Erzurumlu and H. Oktem, "Comparison of response surface model with neural network in determining the surface quality of moulded parts," Materials and Design, vol. 28, no. 2, pp. 459-465, 2007.

[11] B. P. Huang, J. C. Chen, and Y. Li, "Artificial-neural-networksbased surface roughness Pokayoke system for end-milling operations," Neurocomputing, vol. 71, no. 4-6, pp. 544-549, 2008.

[12] M. I. Hossain, A. K. M. Amin, and A. U. Patwari, "Development of an artificial neural network algorithm for predicting the surface roughness in end milling of Inconel 718 alloy," in Proceedings of the International Conference on Computer and Communication Engineering (ICCCE '08), pp. 1321-1324, Kuala Lumpur, Malaysia, May 2008.

[13] I. A. El-Sonbaty, U. A. Khashaba, A. I. Selmy, and A. I. Ali, "Prediction of surface roughness profiles for milled surfaces using an artificial neural network and fractal geometry approach," Journal of Materials Processing Technology, vol. 200, no. 1-3, pp. 271-278, 2008.

[14] Z. Liu, D. Zhang, and H. Qi, "Surface roughness modeling of high speed machining TC4 based on artificial neural network method," in Proceedings of the 1st International Symposium on Systems and Control in Aerospace and Astronautics, pp. 920924, January 2006.

[15] G. Quintana, M. L. Garcia-Romeu, and J. Ciurana, "Surface roughness monitoring application based on artificial neural networks for ball-end milling operations," Journal of Intelligent Manufacturing. In press.

[16] H. Öktem, "An integrated study of surface roughness for modelling and optimization of cutting parameters during end milling operation," International Journal of Advanced Manufacturing Technology, vol. 43, no. 9-10, pp. 852-861, 2009.

[17] A. M. Zain, H. Haron, and S. Sharif, "Application of regression and ANN techniques for modeling of the surface roughness in end milling machining process," in Proceedings of the 3rd Asia International Conference on Modelling and Simulation (AMS '09), pp. 188-193, May 2009.

[18] A. M. Zain, H. Haron, and S. Sharif, "Artificial neural network for predicting machining performance of uncoated carbide (WC-Co) in milling machining operation," in Proceedings of the International Conference on Computer Technology and Development (ICCTD '09), pp. 76-80, November 2009.

[19] I. Escamilla, P. Perez, L. Torres, P. Zambrano, and B. Gonzalez, "Optimization using neural network modeling and swarm intelligence in the machining of titanium (Ti 6Al 4V) alloy," in Proceedings of the 8th Mexican International Conference on Artificial Intelligence (MICAI'09), pp. 33-38, November 2009.

[20] A. M. Zain, H. Haron, and S. Sharif, "Prediction of surface roughness in the end milling machining using artificial neural network," Expert Systems with Applications, vol. 37, no. 2, pp. 1755-1768, 2010. 
[21] M. F. F. Ab. Rashid and M. R. Abdul Lani, "Surface roughness prediction for $\mathrm{CNC}$ milling process using artificial neural network," in Proceedings of the World Congress on Engineering (WCE '10), vol. 3, London, UK, June-July 2010.

[22] C. Brecher, G. Quintana, T. Rudolf, and J. Ciurana, "Use of NC kernel data for surface roughness monitoring in milling operations ," The International Journal of Advanced Manufacturing Technology, vol. 53, no. 9-12, pp. 953-962, 2011.

[23] M. R. Razfar, R. Farshbaf Zinati, and M. Haghshenas, "Optimum surface roughness prediction in face milling by using neural network and harmony search algorithm," International Journal of Advanced Manufacturing Technology, vol. 52, no. 58, pp. 487-495, 2011.

[24] P. B. Huang, W.-J. Shiang, Y.-T. Jou, C. Chang, and C. Ma, "An in-process adaptive control of surface roughness in end milling operations," in Proceedings of the 9th International Conference on Machine Learning and Cybernetics (ICMLC '10), pp. 1191-1194, Qingdao, China, July 2010.

[25] E. S. Topal, "The role of stepover ratio in prediction of surface roughness in flat end milling," International Journal of Mechanical Sciences, vol. 51, no. 11-12, pp. 782-789, 2009.

[26] P. Muñoz-Escalona and P. G. Maropoulos, "Artificial neural networks for surface roughness prediction when face milling Al 7075-T7351," Journal of Materials Engineering and Performance, vol. 19, no. 2, pp. 185-193, 2010.

[27] S. Palani and U. Natarajan, "Prediction of surface roughness in $\mathrm{CNC}$ end milling by machine vision system using artificial neural network based on 2D Fourier transform," The International Journal of Advanced Manufacturing Technology. In press.

[28] V. Tandon and H. El-Mounayri, "A novel artificial neural networks force model for end milling," International Journal of Advanced Manufacturing Technology, vol. 18, no. 10, pp. 693700, 2001.

[29] V. Tandon, H. El-Mounayri, and H. Kishawy, "NC end milling optimization using evolutionary computation," International Journal of Machine Tools \& Manufacture, vol. 42, no. 5, pp. 595-605, 2002.

[30] J. F. Briceno, H. El-Mounayri, and S. Mukhopadhyay, "Selecting an artificial neural network for efficient modeling and accurate simulation of the milling process," International Journal of Machine Tools \& Manufacture, vol. 42, no. 6, pp. 663-674, 2002.

[31] U. Zuperl and F. Cus, "Tool cutting force modeling in ballend milling using multilevel perceptron," Journal of Materials Processing Technology, vol. 153-154, no. 1-3, pp. 268-275, 2004.

[32] H. El-Mounayri, H. Kishawy, and J. Briceno, "Optimization of CNC ball end milling: a neural network-based model," Journal of Materials Processing Technology, vol. 166, no. 1, pp. 50-62, 2005.

[33] U. Zuperl, F. Cus, B. Mursec, and T. Ploj, "A generalized neural network model of ball-end milling force system," Journal of Materials Processing Technology, vol. 175, no. 1-3, pp. 98-108, 2006.

[34] Ş. Aykut, M. Gölcü, S. Semiz, and H. S. Ergür, "Modeling of cutting forces as function of cutting parameters for face milling of satellite 6 using an artificial neural network," Journal of Materials Processing Technology, vol. 190, no. 1-3, pp. 199203, 2007.

[35] J. K. Rai, L. Villedieu, and P. Xirouchakis, "Mill-cut: a neural network system for the prediction of thermo-mechanical loads induced in end-milling operations," International Journal of Advanced Manufacturing Technology, vol. 37, no. 3-4, pp. 256264, 2008.

[36] Y. Chen, W. Long, F. Ma, and B. Zhang, "Cutting force prediction of high-speed milling hardened steel based on BP neural networks," in Proceedings of the 6th International Symposium on Neural Networks (ISNN'09), vol. 56 of Advances in Soft Computing, pp. 571-577, 2009.

[37] S.-T. Seong, K.-T. Jo, and Y.-M. Lee, "Cutting force signal pattern recognition using hybrid neural network in end milling," Transaction of Nonferrous Metals Society of China, vol. 19, supplement 1, pp. s209-s214, 2009.

[38] U. Zuperl, F. Cus, and M. Reibenschuh, "Neural control strategy of constant cutting force system in end milling," Robotics and Computer-Integrated Manufacturing, vol. 27, no. 3, pp. 485-493, 2010.

[39] H. El-Mounayri, J. F. Briceno, and M. Gadallah, "A new artificial neural network approach to modeling ball-end milling," International Journal of Advanced Manufacturing Technology, vol. 47, no. 5-8, pp. 527-534, 2010.

[40] H. Chen, D. Li, S. Huang, and P. Fu, "Study on the cutting force prediction of supercritical material milling," in Proceedings of the 6th International Conference on Natural Computation (ICNC'10), pp. 1148-1152, 2010.

[41] R. K. Dutta, S. Paul, and A. B. Chattopadhyay, "Applicability of the modified back-propagation algorithm in tool condition monitoring for faster convergence," Journal of Materials Processing Technology, vol. 98, no. 3, pp. 299-309, 2000.

[42] R. E. Haber and A. Alique, "Intelligent process supervision for predicting tool wear in machining processes," Mechatronics, vol. 13, no. 8-9, pp. 825-849, 2003.

[43] J. C. Chen and J. C. Chen, "An artificial-neural-networksbased in-process tool wear prediction system in milling operations," International Journal of Advanced Manufacturing Technology, vol. 25, no. 5-6, pp. 427-434, 2005.

[44] R. K. Dutta, S. Paul, and A. B. Chattopadhyay, "The efficacy of back propagation neural network with delta bar delta learning in predicting the wear of carbide inserts in face milling," International Journal of Advanced Manufacturing Technology, vol. 31, no. 5-6, pp. 434-442, 2006.

[45] U. Zuperl, E. Kiker, and K. Jezernik, "Adaptive force control in high-speed machining by using a system of neural networks," in Proceedings of the IEEE International Symposium on Industrial Electronics (ISIE '06), vol. 1, pp. 148-153, Montreal, Canada, July 2006.

[46] N. Ghosh, Y. B. Ravi, A. Patra et al., "Estimation of tool wear during CNC milling using neural network-based sensor fusion," Mechanical Systems and Signal Processing, vol. 21, no. 1, pp. 466-479, 2007.

[47] X. Chuangwen, W. Xiaohong, L. Wencui, and F. Xing, "Milling wear monitoring study based on cutting power," in Proceedings of the International Conference on Advanced Computer Control (ICACC '09), pp. 671-674, January 2009.

[48] L. Guo, H. Zhang, Y. Qi, and Z. Wei, "Study on tool wear monitoring based on multi-source information fusion," in Proceedings of the 4th International Conference on Intelligent Computing (ICIC '08), vol. 5227 of Lecture Notes in Computer Science, pp. 107-114, Shanghai, China, 2008.

[49] P. Palanisamy, I. Rajendran, and S. Shanmugasundaram, "Prediction of tool wear using regression and ANN models in end-milling operation," International Journal of Advanced Manufacturing Technology, vol. 37, no. 1-2, pp. 29-41, 2008. 
[50] C. Bruni, L. d'Apolito, A. Forcellese, F. Gabrielli, and M. Simoncini, "Surface roughness modelling in finish face milling under MQL and dry cutting conditions," International Journal of Material Forming, vol. 1, supplement 1, pp. 503-506, 2008.

[51] D. Brezak, D. Majetic, T. Udiljak, and J. Kasac, "Flank wear regulation using artificial neural networks," Journal of Mechanical Science and Technology, vol. 24, no. 5, pp. 10411105, 2010. 



Submit your manuscripts at

http://www.hindawi.com
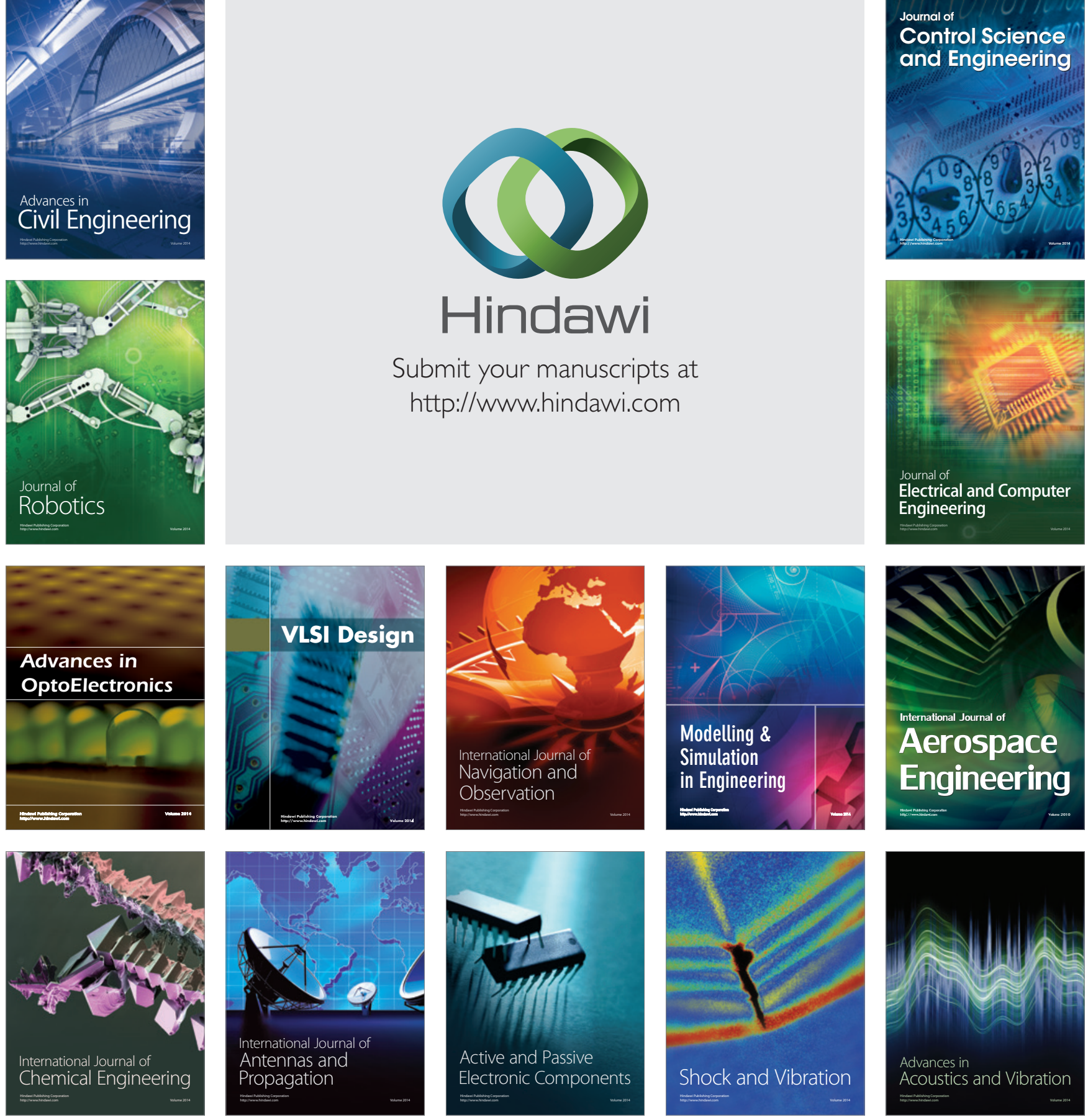